\title{
Pengembangan Aplikasi Ujian Akhir Semester Berbasis Komputer Mata Pelajaran Bahasa Indonesia Pada Siswa Kelas X Akuntansi di SMK Negeri 1 Samarinda Semester Genap Tahun Pembelajaran 2018/2019
}

\author{
Fitriani $^{1}$, Arif Harjanto ${ }^{2}$ \\ ${ }^{1,2}$ Universitas Mulawarman \\ lfitriani.el2011@gmail.com1, 2arif.harjanto@ft.unmul.ac.id2
}

\begin{abstract}
Develop computer based test applications and test the feasibility of computer based test applications and determine whether the computer based test applications can support the implementation of the exam. For the development of this applications the researcher uses Microsoft Access 2013 as a database and for the programming language used is Microsoft Visual Basic 6.0. Based on the result of the study, it can be concluded that the computer based test application is in accordance with its purpose, which is to facilitate users both teachers and students in implementing the computer base test applications for Indonesian Class $X$ Accounting subjects at SMK Negeri 1 Samarinda in the even of the 2018/2019 academic year.
\end{abstract}

Keywords: Computer Based Test Applications; Waterfall; Visual Basic 6.0

\begin{abstract}
Abstrak
Mengembangkan aplikasi Ujian Akhir Semester berbasis komputer dan menguji kelayakan aplikasi Ujian Akhir Semester berbasis komputer serta untuk mengetahui apakah aplikasi Ujian Akhir Semester dapat menunjang dalam pelaksanaan ujian. Untuk pengembangan aplikasi ini peneliti menggunakan Microsoft Access 2013 sebagai database dan untuk bahasa pemrograman yang digunakan adalah Microsoft Visual Basic 6.0. Berdasarkan hasil penelitian maka dapat disimpulkan bahwa aplikasi Ujian Akhir Semester ini sudah sesuai dengan tujuannya yaitu dapat memudahkan pengguna baik guru maupun siswa dalam dalam pelaksanaan Ujian Akhir Semester mata pelajaran Bahasa Indonesia kelas X Akuntansi di SMK Negeri 1 Samarinda semester genap tahun pembelajaran 2018/2019.
\end{abstract}

Kata kunci: Aplikasi ujian berbasis komputer; Waterfall; Visual Basic 6.0

\section{PENDAHULUAN}

Ujian merupakan salah satu bentuk evaluasi yang digunakan untuk menilai ketersampaian pelajaran yang telah diajarkan oleh guru kepada murid. Ujian dapat dilakukan dalam berbagai macam format, format itu meliputi ujian pilihan ganda, isian bebas, simulasi, benar atau salah, dan tipe likert (Wibowo, 2014). Menurut Susilowati, S., \& Hidayat, T (2018) ujian merupakan berarti bentuk evaluasi proses belajar mengajar dalam rangka mengukur taraf pencapaian keahlian, karakter serta intelegensia siswa, sehingga menjadikan ujian sebagai tahapan penting dalam proses belajar mengajar. Pada saat ini dunia pendidikan mengalami perkembangan baik dalam proses pengajaran maupun dalam sistem ujian. Ujian Akhir Semester (UAS) adalah kegiatan yang dilakukan oleh satuan pendidikan untuk mengukur hasil pencapaian kompetensi peserta didik dalam satu semester. Di dalam dunia pendidikan ada banyak sistem ujian. Salah satunya adalah sistem ujian manual yang menggunakan media kertas dan alat tulis sebagai penunjang kegiatan ujian. Pada sistem ujian manual tidak lepas dari proses koreksi dan pendataan nilai siswa yang dilakukan secara manual satu- persatu dan tidak memberikan hasil ujian secara real time. Siswa harus menunggu 
berhari-hari untuk mengetahui hasil ujian apakah lulus/tidak dalam mengikuti ujian semester. Ujian dengan sistem berbasis komputer memiliki kelebihan yang tidak mungkin diperoleh pada ujian dengan sistem manual, yaitu pada kecepatan pengolahan hasil. Pada ujian berbasis komputer dalam penggunaanya, sistem ini memberikan hasil evaluasi secara real time. Hal ini sangat menunjang dalam pelaksanaan ujian karena hasil ujian langsung dapat diketahui pada saat itu juga, ketika siswa mengakhiri ujian. Aplikasi Ujian Akhir Semester berbasis komputer ini menggunakan jenis jaringan Local Area Network (LAN) dengan tipe jaringan Client-Server. Client/Server merupakan sebuah aplikasi jaringan terbagi menjadi dua bagian yang terpisah, namun masih merupakan sebuah kesatuan yakni komponen client dan komponen server. Komponen client dijalankan dalam sebuah workstation dan client menangani proses yang menjadi tanggung jawabnya. Jika ada proses yang harus melibatkan data yang tersimpan pada basis data yang terletak di server, barulah client mengadakan hubungan dengan server. Pada bentuk sistem client server untuk memenuhi kebutuhan client akan megirimkan pesan atau perintah query pengambilan data. Selanjutnya server yang menerima pesan tersebut akan menjalankan query tersebut dan hasilnya akan dikirimkan kembali ke client (Komputer, 2010). SMK Negeri 1 Samarinda sebagai salah satu lembaga pendidikan yang formal, dimana sekolah ini masih menggunakan sistem ujian manual. Maka dari itu untuk upaya menindak lanjuti Permendikbud nomor 57 tahun 2015 tentang Ujian Nasional dan Ujian Sekolah, dan agar dapat memudahkan siswa untuk mendapatkan informasi hasil ujian secara real time, dan juga membantu memudahkan guru dalam mengoreksi soal maka dikembangkanlah aplikasi ujian berbasis komputer pada SMK Negeri 1 Samarinda.

\section{KERANGKA TEORI}

\subsection{Aplikasi}

Perangkat lunak atau aplikasi merupakan subkelas perangkat lunak pada komputer yang dimanfaatkan secara langsung oleh pengguna atau user untuk mengerjakan sesuatu yang diinginkan. Biasanya, perangkat lunak sistem dapat mengintegrasikan berbagai fitur teknologi informasi, tetapi tidak menerapkannya secara langsung untuk melakukan tugas yang membuat pengguna nya menjadi lebih mudah. Contoh perangkat lunak aplikasi antara lain seperti lembar kerja, pengolah kata, pemutar media dan lain nya (Kadir, 2009).

\subsection{Tes dan Ujian}

Tes (test) merupakan suatu alat penilaian dalam bentuk tulisan untuk mencatat atau mengamati prestasi siswa yang sejalan dengan target penilaian (Jacobs \& Chase, 1992; Alwasilah, 1996). Tes dapat berupa lisan atau perbuatanan. Sementara itu, menurut Zainul dan Nasution (2001) tes didefinisikan sebagai pertanyaan atau tugas atau seperangkat tugas yang direncanakan untuk memperoleh informasi tentang suatu atribut pendidikan atau suatu atribut psikologis tertentu. Setiap butir pertanyaan atau tugas tersebut mempunyai jawaban atau ketentuan yang dianggap benar. Tes digunakan oleh guru untuk mengukur dan memberikan kesempatan bagi siswa untuk menunjukan prestasi dan hasil belajar siswa yang berkaitan dengan tujuan yang telaj ditentukan.

\subsection{Computer Based Test}

Computer Based Test (CBT) atau dapat disebut dengan Tes Berbasis Komputer pada prinsipnya sama seperti ujian pada umumnya yang menggunakan kertas dan pensil, hanya saja berbeda dalam bentuk penyajian tes kepada peserta nya yaitu dengan menggunakan komputer. Dengan demikian dapat disimpulkan bahwa Computer Based Test (CBT) merupakan suatu cara dalam melakukan proses ujian dengan menggunakan computer (Suryadi, 2015). 


\subsection{Arsitektur Client/Server}

Arsitektur client/server merupakan jaringan komputer yang membedakan fungsi komputer menjadi komputer client dan komputer server (. Pada aplikasi yang menggunaan arsitektur client/server, aplikasi dapat beroperasi secara mandiri walaupun berada ditempat yang berbeda database server akan menerima request berupa perintah-perintah dari komputer client kemudian database server akan mengirimkan jawabannya ke komputer client. Komputer pertama sebagai server (back end) berupa Database Management System (DBMS). Komputer kedua dan seterusnya disebut client (front end).

\section{METODOLOGI PENELITIAN}

\subsection{Model Pengembangan Sistem}

Aplikasi ujian berbasis komputer ini mengacu pada model pengembangan Waterfall yang dijelaskan oleh Ian Sommerville (2011). Model pengembangan Waterfall dipilih karena sesuai dengan kebutuhan peneliti dan secara spesifik model pengembangan ini merupakan model pengembangan untuk aplikasi perangkat lunak. Ian Sommerville menjelaskan bahwa model pengembangan Waterfall terdiri dari lima langkah yaitu:

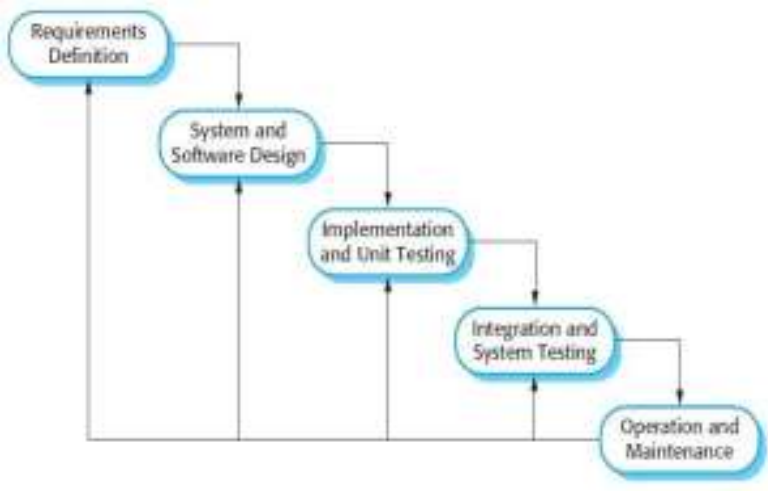

Gambar 1. Model Pengembangan Waterfall

1. Requirements Analysis and Definition: melakukan studi pustaka serta melakukan studi lapangan berupa observasi dan wawancara untuk mendapatkan data.

2. System and Software Design: melanjutkan proses dengan menentukan rencana sistem yang akan dikembangkan dan melakukan perancangan meliputi pembuatan desain tampilan, desain database, dan desain diagram (berupa desain Context Diagram, Data Flow Diagram, Entity Relationship Diagram, Struktur menu, flowchart dan desain interface.

3. Implementation and Unit Testing: dilakukan dengan melakukan pengembangan berupa kode program. Setelah itu dilakukan kegiatan pengujian setiap fungsi kode yang telah dibuat. Apabila masih terdapat error dalam eksekusi program, maka dilakukan perbaikan terhadap kode program yang dikembangkan.

4. Integration and System Testing: dilakukan dengan pengujian White box testing dan Black box testing keseluruhan struktur dan fungsi.

5. Operation and Maintenance: dilakukan pengoperasian di lapangan. Apabila aplikasi sudah layak digunakan maka dilakukan pemeliharaan/maintenance pada aplikasi tersebut. 


\subsection{Metode Pengumpulan Data}

Dalam proses pengumpulan data untuk memperoleh data yang akurat dan meyakinkan dibutuhkan data primer dan data sekunder, maka dilakukan teknik pengambilan data sebagai berikut:

Data Primer, yaitu data yang diperoleh secara langsung dari tempat penelitian. Teknik pengumpulan data ini adalah sebagai berikut:

a. Metode Observasi, merupakan pendekatan atau teknik dalam mendapatkan data-data primer dengan cara pengamatan secara langsung terhadap obyek datanya.

b. Metode Wawancara, Teknik pengumpulan data yang dilaksanakan dengan berkomunikasi secara langsung dengan pemangku kepentingan untuk mendapatkan informasi maupun data-data dari responden.

c. Metode Angket, merupakan teknik pengumpulan data melalui formulir-formulir yang berisi pertanyaanpertanyaan yang diajukan secara tertulis.

Data Sekunder, data ini di dapat dengan cara pengumpulan data menggunakan metode sebagai berikut:

a. Studi Literatur, merupakan teknik pengumpulan data dari berbagai literatur serta penelitian-penelitian yang sesuai untuk dijadikan landasan penelitian ini.

b. Dokumentasi, teknik pengumpulan data dari dokumentasi internet ataupun sumber data dan informasi lain yang mendukung pada penelitian ini

\subsection{Teknik Analisis Data}

Data yang telah terkumpul perlu diolah dan dianalisis. Peneliti harus cermat dalam menentukan pola analisis bagi data penelitiannya. Berikut ada dua metode analisis yang dipakai dalam menganalisis data, yaitu:

1. Analisis Deskriptif Kualitatif

2. Analisis Kuantitatif

\section{HASIL DAN PEMBAHASAN}

\subsection{Desain Context Diagram}

Context diagram yaitu diagram paling tidak detail dari sebuah sistem informasi yang menggambarkan aliran-aliran data yang masuk dan keluar dari sistem. Berikut adalah context diagram dari aplikasi Ujian Akhir Semester berbasis komputer dapat dilihat pada gambar 2. 


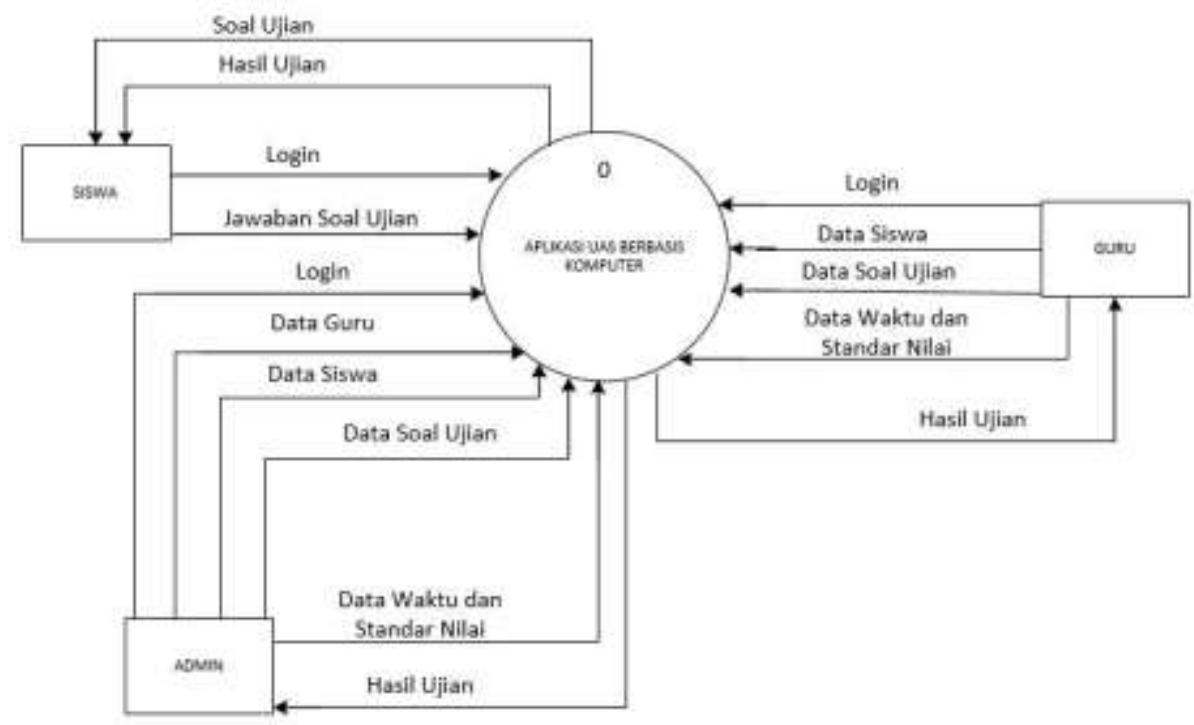

Gambar 2. Context Diagram

\subsection{Desain Data Flow Diagram}

DFD adalah Diagram yang menggambarkan suatu sistem yang telah ada atau sistem baru yang akan dikembangkan secara logika, tanpa mempertimbangkan lingkungan fisik dimana data tersebut mengalir atau dimana data tersebut akan disimpan. Berikut DFD dari aplikasi Ujian Akhir Semester berbasis komputer dapat dilihat pada gambar 3.

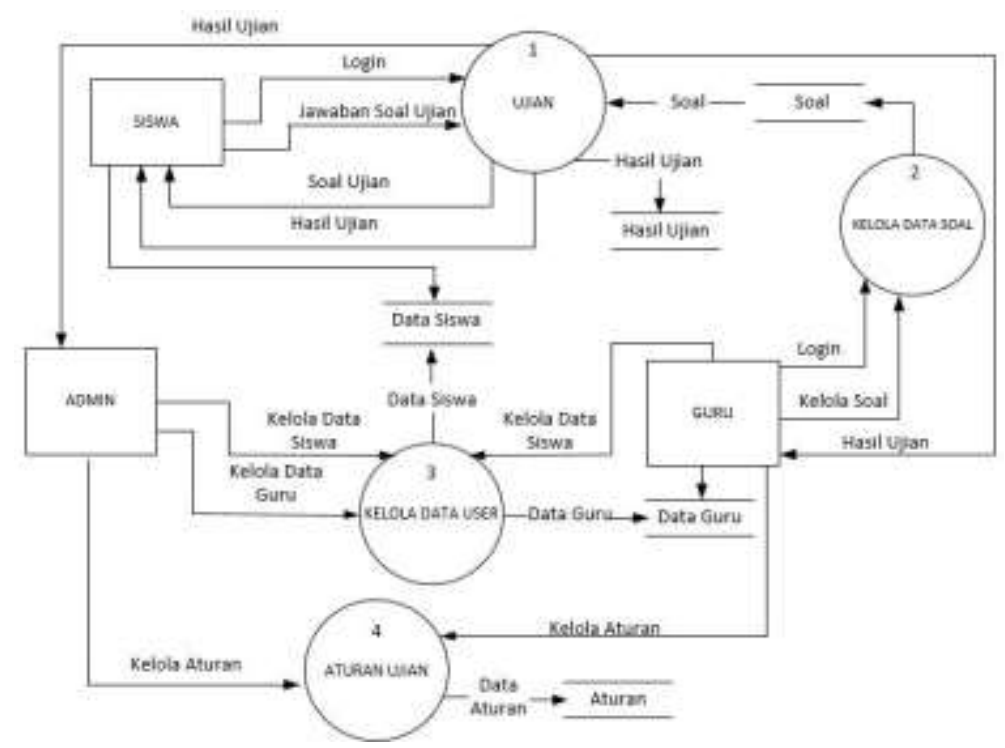

Gambar 3. Data Flow Diagram

\subsection{Entity Relationship Diagram}

ERD untuk menjelaskan hubungan antara data dalam Database berdasarkan objek-objek dasar data yang mempunyai hubungan antar relasi. Adapun ERD dari aplikasi Ujian Akhir Semester berbasis komputer seperti berikut: 


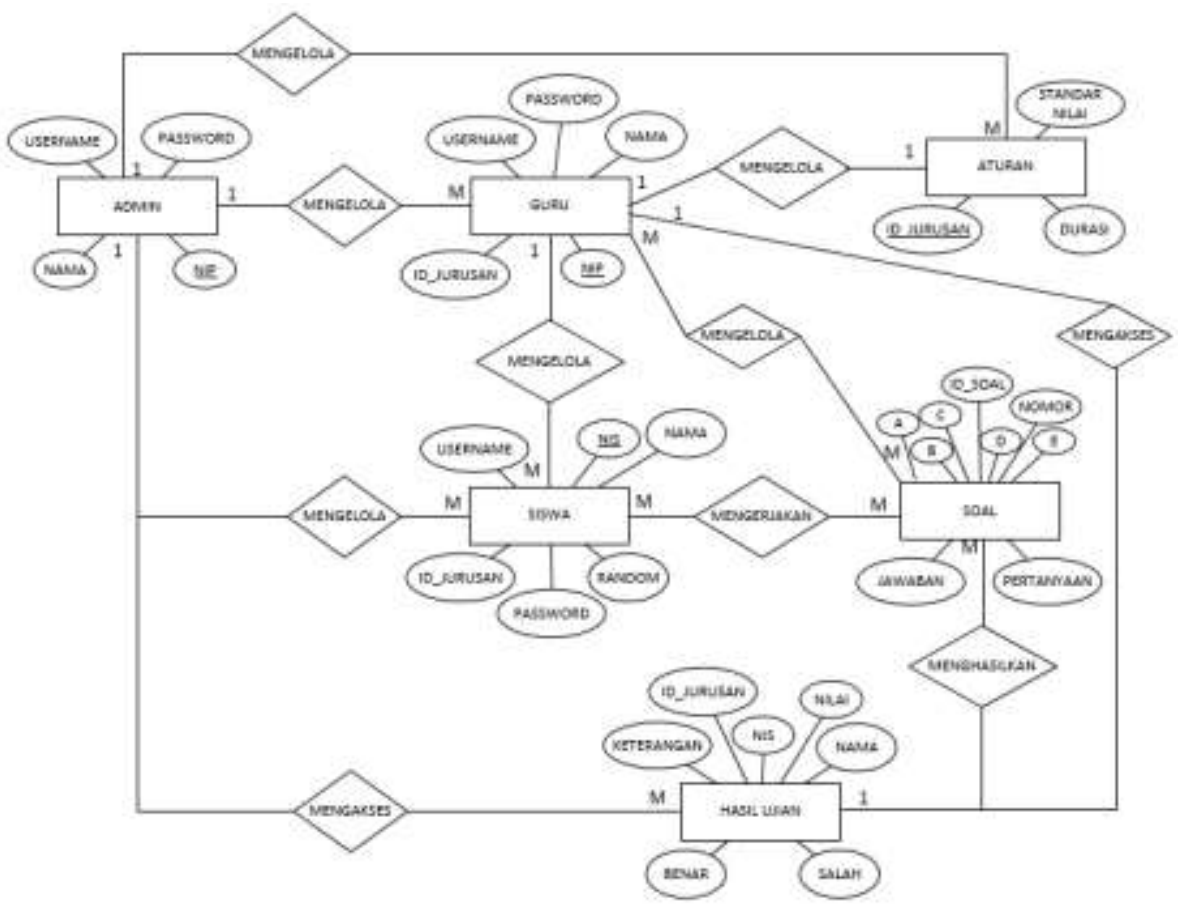

Gambar 4. Entity Relationship Diagram

\subsection{Desain Interface}

Perancangan desain interface bertujuan untuk memberikan gambaran tentang aplikasi Ujian Akhir Semester berbasis komputer yang akan dikembangkan. sehingga akan mempermudah dalam mengimplementasikan aplikasi tersebut. berikut ini adalah tampilan desain interface aplikasi Ujian Akhir Semester berbasis komputer. Dapat dilihat pada Gambar 5 sampai dengan Gambar 8.

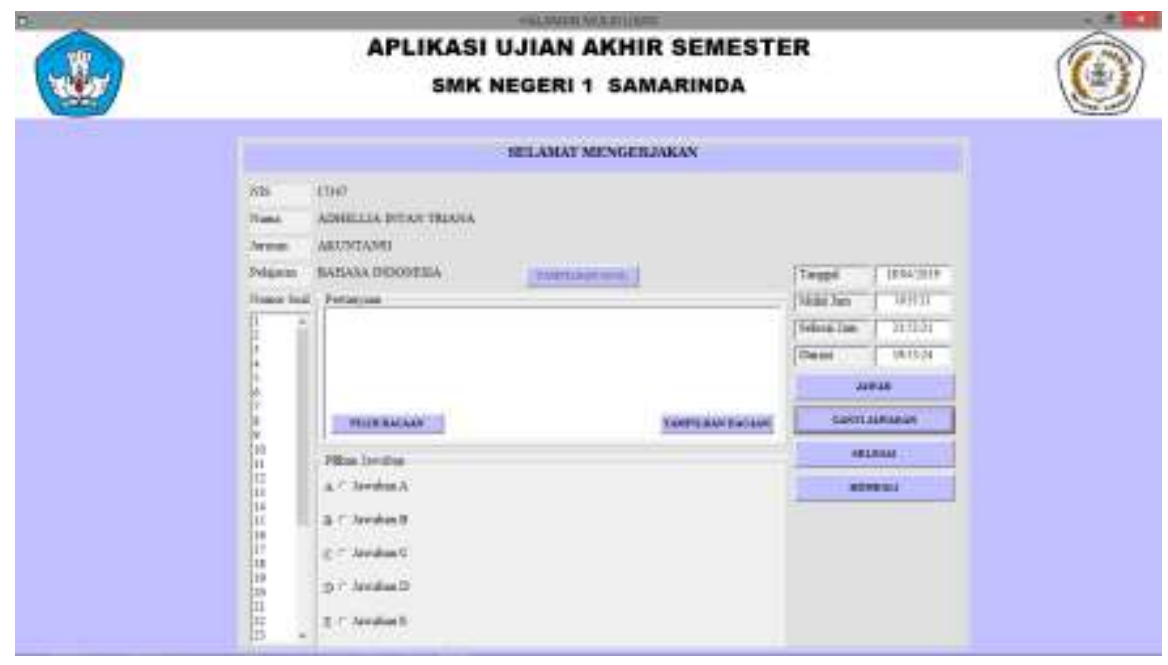

Gambar 5. Halaman Siswa Mengerjakan Ujian 


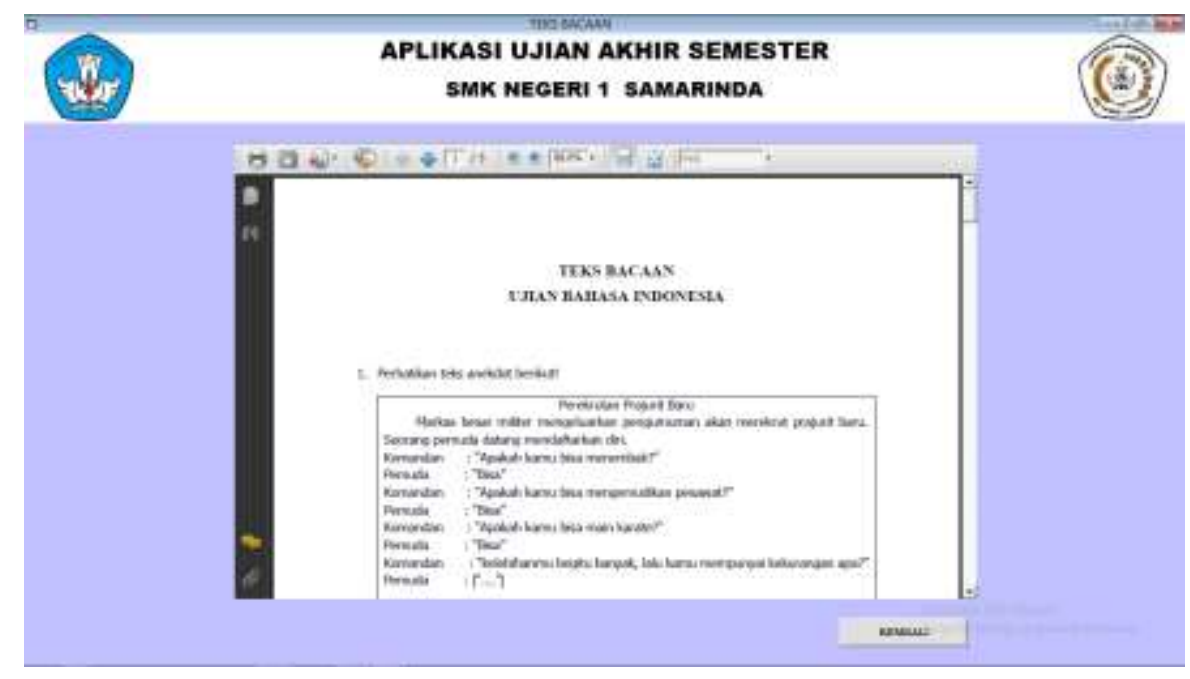

Gambar 6. Halaman Siswa Melihat Naskah Soal

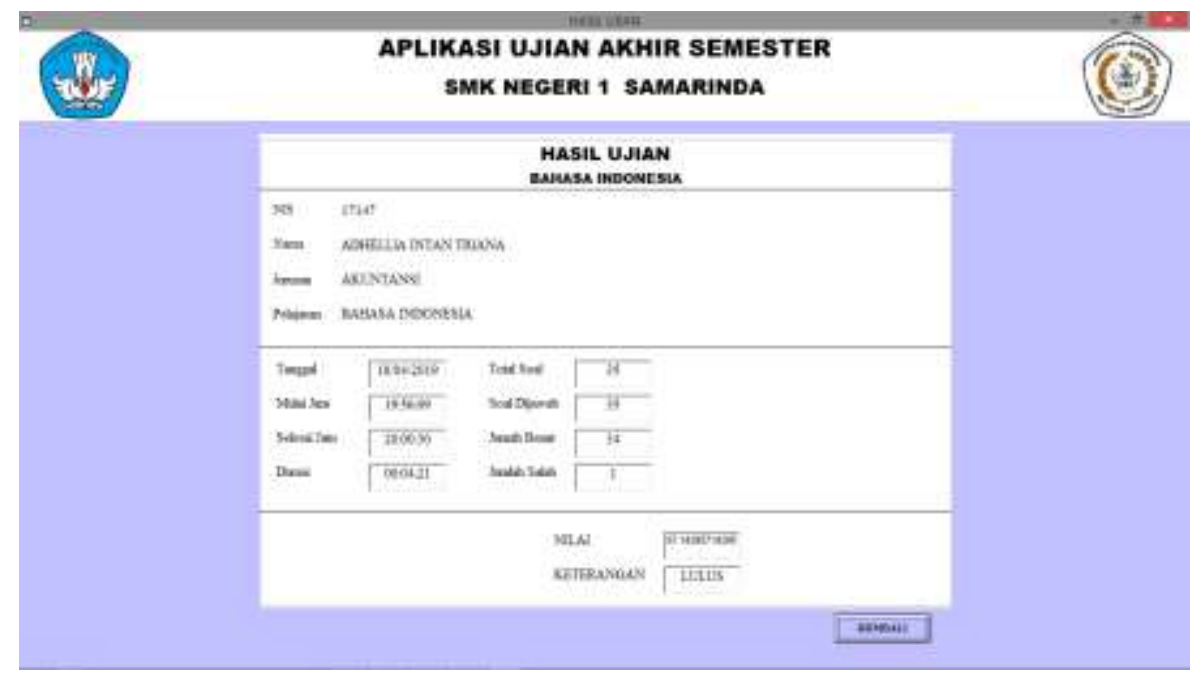

Gambar 7. Halaman Siswa Selesai Ujian

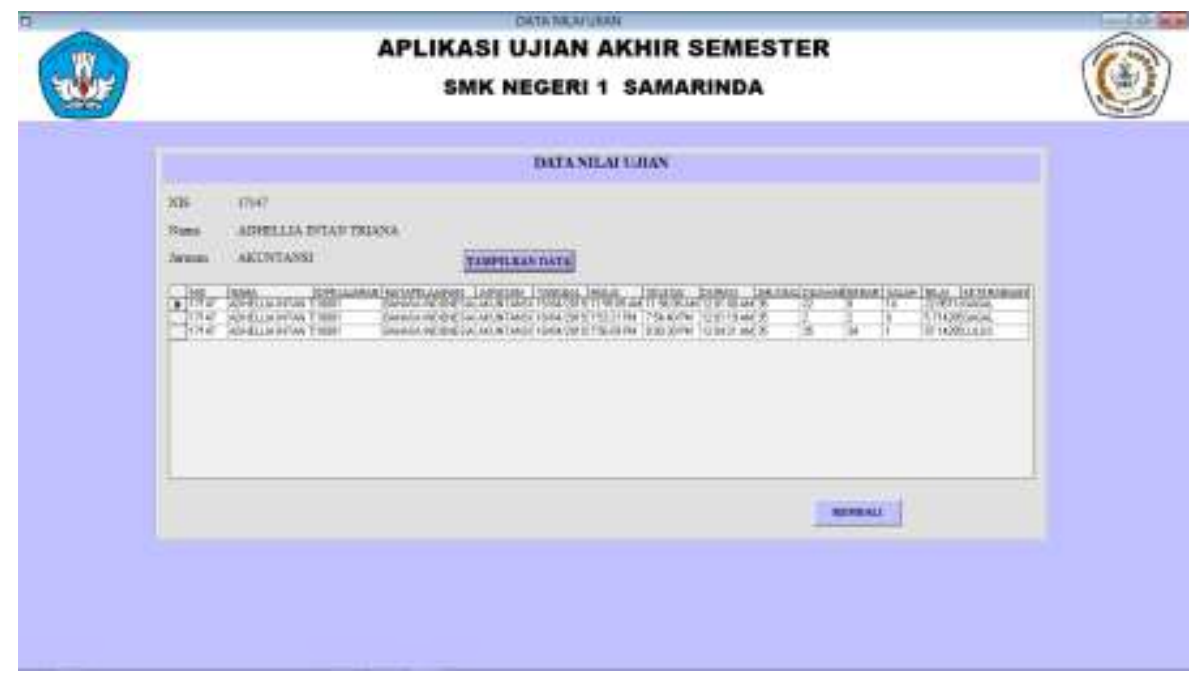

Gambar 8. Halaman Siswa Melihat Hasil Ujian 


\subsection{Hasil Data Pengujian}

Kegiatan pengujian dilakukan dari aplikasi yang dikembangkan. Pengujian dilakukan oleh ahli validasi media, ahli Computer Based Test (CBT), guru dan siswa. Adapun hasil analisis pengujian untuk masing-masing validator adalah seperti tabel berikut:

Tabel 1. Data Hasil Penilaian oleh Ahli validasi media

\begin{tabular}{|c|c|c|c|c|c|c|c|}
\hline \multirow[b]{2}{*}{ No. } & \multirow[b]{2}{*}{ Komponen } & \multicolumn{2}{|c|}{ Validator } & \multirow{2}{*}{$\begin{array}{c}\text { Rerata } \\
\text { Jumlah } \\
\text { Skor }\end{array}$} & \multirow{2}{*}{$\begin{array}{c}\text { Jumlah } \\
\text { Skor } \\
\text { Maks }\end{array}$} & \multirow{2}{*}{$\begin{array}{c}\text { Persentase } \\
(\%)\end{array}$} & \multirow[b]{2}{*}{ Kategori } \\
\hline & & $\begin{array}{c}\text { Ahli Validasi } \\
\text { Media } 1\end{array}$ & $\begin{array}{c}\text { Ahli Validasi } \\
\text { Media } 2\end{array}$ & & & & \\
\hline 1 & Content & 26 & 23 & 24,5 & 30 & $81,7 \%$ & Baik \\
\hline 2 & Interface & 49 & 41 & 45 & 55 & $81,8 \%$ & Baik \\
\hline 3 & Navigation & 25 & 16 & 20,5 & 25 & $82 \%$ & Baik \\
\hline 4 & Configuration & 15 & 11 & 13 & 15 & $86,7 \%$ & Sangat Baik \\
\hline 5 & Security & 11 & 10 & 10,5 & 15 & $70 \%$ & Baik \\
\hline \multicolumn{2}{|c|}{ Skor Total } & 126 & 101 & 113,5 & 140 & $81,07 \%$ & Baik \\
\hline
\end{tabular}

Sumber: Hasil Penelitian di Lapangan

Tabel 2. Data Hasil Penilaian oleh Ahli Media CBT

\begin{tabular}{llcccc}
\hline No. & Komponen & Validator & Jumlah Skor Maks & $\begin{array}{c}\text { Persentase } \\
(\mathbf{\%})\end{array}$ & Kategori \\
\cline { 3 - 5 } & Ahli CBT & & $100 \%$ & Sangat Baik \\
\hline 1 & Correctness & 25 & 25 & $95 \%$ & Sangat Baik \\
2 & Reliability & 38 & 40 & $100 \%$ & Sangat Baik \\
3 & Integrity & 20 & 20 & $86,7 \%$ & Sangat Baik \\
4 & Usability & 26 & 30 & $\mathbf{9 4 , 7 8 \%}$ & Sangat Baik \\
\hline
\end{tabular}

Sumber: Hasil Penelitian di Lapangan

Berdasarkan pengujian aplikasi Ujian Akhir Sekolah berbasis komputer yang dilakukan oleh ahli yaitu ahli validasi media dan ahli CBT maka dapat dibuat tabel kesimpulan seperti pada Tabel 3 berikut:

Tabel 3. Persentase Nilai Pengujian Aplikasi Oleh Ahli

\begin{tabular}{llcc}
\hline No. & Komponen & Persentase (\%) & Tingkat Kelayakan \\
\hline 1. & Content & $81,7 \%$ & Baik \\
2. & Interface & $81,8 \%$ & Baik \\
3. & Navigation & $82 \%$ & Baik \\
4. & Configuration & $86,7 \%$ & Sangat Baik \\
5. & Security & $70 \%$ & Baik \\
6. & Correctness & $100 \%$ & Sangat Baik \\
7. & Reliability & $95 \%$ & Sangat Baik \\
8. & Integrity & $100 \%$ & Sangat Baik \\
\hline
\end{tabular}




9. Usability $\quad 86,7 \% \quad$ Sangat Baik

Sumber: Hasil Penelitian di Lapangan

Grafik berisi kesimpulan penilaian ahli validasi media dan ahli CBT ditampilkan pada Gambar 9.

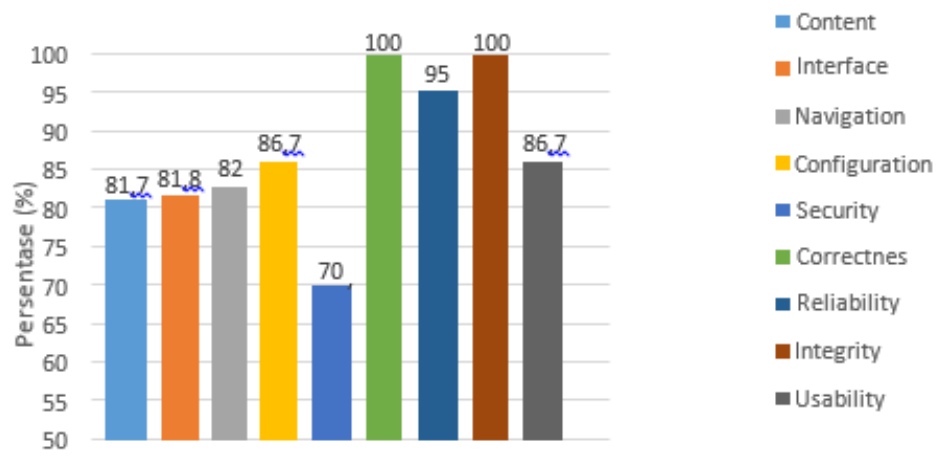

Gambar 9. Grafik Hasil Penilaian Ahli

Tabel 4. Data Hasil Pegujian oleh Guru

\begin{tabular}{llccc}
\hline No. & Nama Guru & Jumlah Skor & Skor Maks & Persentase (\%) \\
\hline 1 & Noor Aidawati, M.Pd & 69 & 75 & $92 \%$ \\
2 & Sri Wulandari & 57 & 75 & $76 \%$ \\
\hline Skor Total & $\mathbf{1 2 6}$ & $\mathbf{1 5 0}$ & $\mathbf{8 4 \%}$ \\
\hline Rerata Skor & $\mathbf{6 3}$ & $\mathbf{7 5}$ & $\mathbf{8 4 \%}$ \\
\hline Kategori & & & Baik \\
\hline
\end{tabular}

Sumber: Hasil Penelitian di Lapangan

Tabel 5. Data Hasil Pengujian oleh Siswa

\begin{tabular}{llccc}
\hline No. & \multicolumn{1}{c}{ Nama Siswa } & $\begin{array}{c}\text { Jumlah } \\
\text { Skor }\end{array}$ & $\begin{array}{c}\text { Skor } \\
\text { Maks }\end{array}$ & $\begin{array}{c}\text { Persentase } \\
(\%)\end{array}$ \\
\hline 1. & Adhellia Intan Triana & 68 & 75 & $90,67 \%$ \\
2. & Ahmad Yahya & 69 & 75 & $92 \%$ \\
3. & Alda Febrianti & 67 & 75 & $89,33 \%$ \\
4. & Ananda Putri Dewi & 71 & 75 & $94,67 \%$ \\
5. & Ananta Adelia Putri & 55 & 75 & $73,33 \%$ \\
6. & Andrianita Ayu Karina & 69 & 75 & $92 \%$ \\
7. & Anisa Dwi Ananda & 58 & 75 & $77,33 \%$ \\
8. & Arsalan Musyaffa & 63 & 75 & $84 \%$ \\
9. & Aulia Fitriani & 62 & 75 & $82,67 \%$ \\
10. & Azka Candra Adi S & 63 & 75 & $84 \%$ \\
11. & Bulan Nadia Oktavie G. & 68 & 75 & $90,67 \%$ \\
12. & Bulan Oktavia & 60 & 75 & $80 \%$ \\
13. & Desi Chomsiawati M & 72 & 75 & $96 \%$
\end{tabular}




\begin{tabular}{|c|c|c|c|c|}
\hline 14. & Fauziyah Salmaa Az Z & 61 & 75 & $81,33 \%$ \\
\hline 15. & Imelian Sinmi & 60 & 75 & $80 \%$ \\
\hline 16. & Irmawati & 51 & 75 & $68 \%$ \\
\hline 17. & Joyya Rahayu & 66 & 75 & $88 \%$ \\
\hline 18. & Maya Liera Evanata & 68 & 75 & $90,67 \%$ \\
\hline 19. & Mei Cien Lianto Lau & 64 & 75 & $85,33 \%$ \\
\hline 20. & Melita Banne & 72 & 75 & $96 \%$ \\
\hline 21. & Nadia Septiana & 71 & 75 & $94,67 \%$ \\
\hline 22. & Najah Riggahetty & 61 & 75 & $81,33 \%$ \\
\hline 23. & Nassya Octaviany S & 68 & 75 & $90,67 \%$ \\
\hline 24. & Nesa Erviana Sabila & 73 & 75 & $97,33 \%$ \\
\hline 25. & Nisrina Yumna & 56 & 75 & $74,67 \%$ \\
\hline 26. & Nur Aidina Amelia & 59 & 75 & $78,67 \%$ \\
\hline 27. & Nurlaila Rahmarezkya & 28 & 75 & $37,33 \%$ \\
\hline 28. & Putri Ayu K & 65 & 75 & $86,67 \%$ \\
\hline 29. & Rabiatun Naili & 73 & 75 & $97,33 \%$ \\
\hline 30. & Ratnya Sabita Nur M & 60 & 75 & $80 \%$ \\
\hline 31. & Renata Daiva Adista & 72 & 75 & $96 \%$ \\
\hline 32. & Syahfitriani & 63 & 75 & $84 \%$ \\
\hline 33. & Waliyah & 59 & 75 & $78,67 \%$ \\
\hline 34. & Yeni Novia Setiawati & 64 & 75 & $85,33 \%$ \\
\hline & Skor Total & 2159 & 2550 & $84,67 \%$ \\
\hline & Rerata Skor & 63,5 & 75 & $84,67 \%$ \\
\hline & Kategori & \multicolumn{3}{|c|}{ Sangat Baik } \\
\hline
\end{tabular}

Tabel 6. Persentase Nilai Pengujian Aplikasi Oleh User

\begin{tabular}{llcc}
\hline No. & Pengguna & Persentase $(\%)$ & Tingkat Kelayakan \\
\hline 1. & Guru & $84 \%$ & Sangat Baik \\
2. & Siswa & $84,67 \%$ & Sangat Baik \\
\hline \multicolumn{2}{l}{ Sumber: Hasil Penelitian }
\end{tabular}

Grafik berisi kesimpulan penilaian user yaitu guru dan siswa ditampilkan pada Gambar 10.

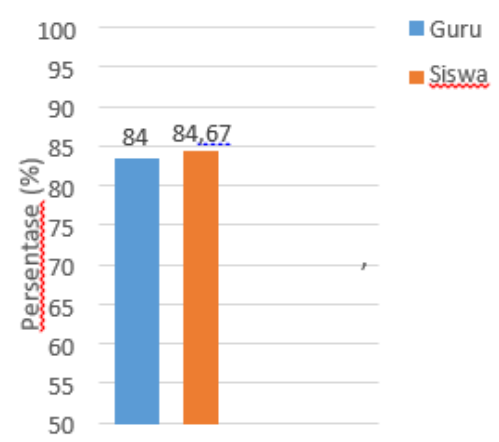

Gambar 10. Grafik Hasil Penilaian User 


\section{KESIMPULAN}

Berdasarkan data yang telah diperoleh dan pembahasan yang telah diuraikan tentang pengembangan aplikasi Ujian Akhir Semester berbasis komputer, maka dapat disimpulkan sebagai berikut.

a. Produk akhir berupa aplikasi Ujian Akhir Semester berbasis komputer untuk pelajaran Bahasa Indonesia kelas X Akuntansi di SMK Negeri 1 Samarinda yang dikembangkan menggunakan bahasa pemrograman Microsoft Visual Basic 6.0 dan menggunakan database Microsoft Access 2013 dengan tambahan fitur untuk mengganti jawaban, running time dan random soal.

b. Aplikasi Ujian Akhir Semester berbasis komputer telah di uji dan mendapatkan penilaian oleh ahli validasi media dengan nilai rerata jumlah skor 113,5 atau $81,07 \%$ dari jumlah skor maksimum sehingga masuk dalam kategori baik, penilaian oleh ahli CBT (Computer Based Test) dengan nilai rerata jumlah skor 109 atau 94,78\% dari jumlah skor maksimum sehingga masuk dalam kategori sangat baik, penilaian oleh guru dengan nilai rerata jumlah skor 63 atau 84\% dari jumlah skor maksimum sehingga masuk dalam kategori baik, dan penilaian oleh siswa dengan nilai rerata jumlah skor 63,5 atau 84,67\% dari jumlah skor maksimum sehingga masuk dalam kategori sangat baik. Berdasarkan penilaian tersebut maka dapat dikatakan aplikasi Ujian Akhir Semester berbasis komputer sangat layak untuk digunakan karena berada pada kategori penilaian sangat baik.

c. Aplikasi Ujian Akhir Semester berbasis komputer dapat menunjang pelaksanaan ujian dengan proses koreksi hasil ujian langsung dilakukan oleh sistem sehingga dapat menampilkasi hasil ujian secara real time.

\section{DAFTAR PUSTAKA}

Azies, Alwasilah., 1996. Pokok - Pokok Keterampilan Mengajar. Surabaya FBS UNESA

Asmawi Zainul \& Noehi Nasution., 2001. Penilaian Hasil Belajar. Jakarta: Dirjen Dikti.

D. Sukrianto., 2019. Summary for Policymakers,” in Climate Change 2013 - The Physical Science Basis, vol. 53, no.

9. Intergovernmental Panel on Climate Change, Ed. Cambridge: Cambridge University Press. pp. 1-30.

Jacobs, Chase., 1992. Developing and using test effectively. San Fransisco: Jossey-Bass Publishers

Kadir, Abdul., 2009. Membuat Aplikasi Web dengan PHP+Database MySQL. Yogyakarta: Penerbit Andi

Komputer, W., 2010. Panduan Aplikatif dan Solusi Membuat Aplikasi Client erver dengan Visual Basic 2008.

Yogyakarta: Penerbit Andi

Sommerville, I., 2011. Software Engineering. Wesley: Addison.

Susilowati, S., \& Hidayat, T., 2018. Rancang Bangun Sistem Informasi Ujian Online (Studi Kasus Pada SMAN 58 Jakarta). Jurnal Teknik Komputer, 4(1), 30-36

Suryadi, Andri., 2015. Perancangan Aplikasi Tes Berbasis Komputer (CBT) Menggunakan Pendekatan Terstruktur

Untuk Penerimaan Mahasiswa Baru Di Perguruan Tinggi." JURNAL PETIK 1.1. 68-81.

Wibowo, Eko Wahyu., 2014. Computer-Based Test (CBT) Sebagai Sarana Evaluasi Pembelajaran 